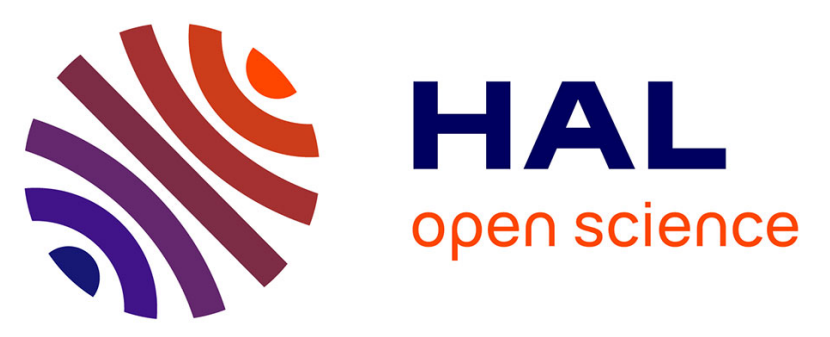

\title{
Advantages of Covalent Immobilization of Metal-Salophen on Amino-Functionalized Mesoporous Silica in Terms of Recycling and Catalytic Activity for CO 2 Cycloaddition onto Epoxides
}

Matthieu Balas, Sébastien Beaudoin, Anna Proust, Franck Launay, Richard

Villanneau

\section{To cite this version:}

Matthieu Balas, Sébastien Beaudoin, Anna Proust, Franck Launay, Richard Villanneau. Advantages of Covalent Immobilization of Metal-Salophen on Amino-Functionalized Mesoporous Silica in Terms of Recycling and Catalytic Activity for CO 2 Cycloaddition onto Epoxides. European Journal of Inorganic Chemistry, 2021, 2021 (16), pp.1581-1591. 10.1002/ejic.202100150 . hal-03485785

\author{
HAL Id: hal-03485785 \\ https://hal.science/hal-03485785
}

Submitted on 17 Dec 2021

HAL is a multi-disciplinary open access archive for the deposit and dissemination of scientific research documents, whether they are published or not. The documents may come from teaching and research institutions in France or abroad, or from public or private research centers.
L'archive ouverte pluridisciplinaire $\mathbf{H A L}$, est destinée au dépôt et à la diffusion de documents scientifiques de niveau recherche, publiés ou non, émanant des établissements d'enseignement et de recherche français ou étrangers, des laboratoires publics ou privés. 


\title{
Advantages of Covalent Immobilization of Metal-Salophen on Amino-Functionalized Mesoporous Silica in Terms of Recycling and Catalytic Activity for $\mathrm{CO}_{2}$ Cycloaddition onto Epoxides
}

\author{
Matthieu Balas, ${ }^{[a, b]}$ Sébastien Beaudoin, ${ }^{[a, b]}$ Anna Proust, ${ }^{[a]}$ Franck Launay, ${ }^{*[b]}$ and \\ Richard Villanneau*[a] \\ Dedicated to the memory of Professor Michel Che
}

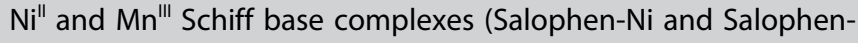
$\mathrm{MnCl}$ ) bearing a pending carboxylic group were prepared and characterized. Both complexes were grafted onto a mesoporous amino-functionalized SBA-15 silica, by formation of an amide function between the propylamine groups of the support and the carboxylic acid functions of the salophen ligand (corresponding respective to $1.30 \mathrm{wt} . \%$ of $\mathrm{Ni}$ and $1.06 \mathrm{wt} . \%$ of $\mathrm{Mn}$ ). The co-catalytic behaviour of the free and grafted complexes was then evaluated in the $\mathrm{CO}_{2}$ cycloaddition reaction onto styrene oxide, using tetra-butylammonium bromide $\left({ }^{n-} \mathrm{Bu}_{4} \mathrm{NBr}\right)$ as the main catalyst. In homogeneous conditions, the $\mathrm{Mn}^{\text {III }}$ Schiff base complex and the $\mathrm{Ni}$ " one, to a lesser extent, behave as efficient co-catalysts for this reaction (styrene conversion of $100 \%$ and $65 \%$ respectively after $3 \mathrm{~h}$ at $120^{\circ} \mathrm{C}$, under 15 bars of
$\mathrm{CO}_{2}$ ). Upon immobilization at the surface of the aminofunctionalized SBA-15, we showed that the co-catalytic activity of the less efficient one, i.e. $\mathrm{Ni}^{2+}$ salophen complex, could be enhanced (reaching a full conversion after $7 \mathrm{~h}$ ), hence highlighting a potential synergistic effect between the unused amine functions of the support and the $\mathrm{Ni}^{2+}$ salophen cocatalyst. Both salophen complexes were successfully re-used in homogeneous conditions or after their immobilization without any appreciable loss of activity. This work is only a first step towards a completely heterogeneous catalytic system, in which the tetraalkylammonium halide catalyst and the metal-salophen co-catalyst will both be covalently anchored on the same support. $\square \square$ Dear author, please check whether the numbering and hierarchy of the headlines are correct - they were not numbered consistently $\square \square$

\section{Introduction}

The large amounts of carbon dioxide released to the atmosphere by human activities significantly contribute to the greenhouse effect. In this context, methods using $\mathrm{CO}_{2}$ as a renewable, abundant C1-source to produce valuable chemicals are regarded with large interest and research concerning $\mathrm{CO}_{2}$ transformation has led to significant

[a] M. Balas, S. Beaudoin, Prof. A. Proust, Dr. R. Villanneau Sorbonne Université, CNRS, Campus Pierre et Marie Curie Institut Parisien de Chimie Moléculaire, CNRS UMR 8232 4 Place Jussieu, 75005 Paris, France

E-mail: richard.villanneau@sorbonne-universite.fr http://www.ipcm.fr/villanneau-richard

[b] M. Balas, S. Beaudoin, Prof. F. Launay Sorbonne Université, CNRS, Campus Pierre et Marie Curie Lab. de Réactivité de Surface, CNRS UMR 7197 4 Place Jussieu, 75005 Paris, France

E-mail: franck.launay@sorbonne-universite.fr http://www.Irs.upmc.fr/en/personal-page-of-researchers/franck-launay. html

Supporting information for this article is available on the WWW under https://doi.org/10.1002/ejic.202100150 progress. ${ }^{[1-10]}$ In this context, $\mathrm{CO}_{2}$ coupling reactions with epoxides leading to useful cyclic carbonates ${ }^{[8-14]}$ have attracted particular attention in the community. $\mathrm{CO}_{2}$ industrial applications already exist but need to be much more developed. Valuable products such as carboxylic acids, carbamates and carbonates can be obtained. ${ }^{[15]}$ In such synthesis, carbon dioxide behaves as a green reagent as the result of its direct reaction with epoxides avoiding the use of phosgene, an extremely toxic reagent, and the formation of by-products. ${ }^{[16]}$ Ethylene and propylene carbonates are already obtained at industrial scale by the reaction of $\mathrm{CO}_{2}$ with epoxides in the presence of organocatalysts such as quaternary ammonium $\left(\mathrm{NR}_{4}{ }^{+}, \mathrm{X}^{-}\right)$or phosphonium $\left(\mathrm{PR}_{4}{ }^{+}, \mathrm{X}^{-}\right)$salts (mainly halogenated ones). Reaction conditions are however severe with temperatures and pressures of $120^{\circ} \mathrm{C}$ and $40 \mathrm{bar}$, respectively. ${ }^{[17]}$ According to recent studies, milder conditions can be used when quaternary ammonium salts (QAS) are combined with co-catalysts, ${ }^{[8-14,18-27]}$ generally hydrogen bond donor compounds ${ }^{[8-10]}$ or metal complexes. ${ }^{[11-14]}$ The latter provide Lewis acidity and thus, facilitate the nucleophilic attack of the activated epoxide by counter-anions of QAS. In this regard, transition metal complexes (especially Schiff bases and porphyrins complexes) are particularly promising ${ }^{[28-29]}$ Salen-type compounds have been introduced very early by North ${ }^{[18]}$ and Zhang, ${ }^{[19]}$ then porphyrins by Ema $^{[30]}$ and, more recently, Schiff bases with 4 nitrogen atoms 
(BS4N) by Christ and Masdeu-Bulto. ${ }^{[28]}$ Some of the systems involving metal complexes and QAS operate at room temperature and at atmospheric pressure. ${ }^{[31]}$ In recent years, significant advances have led to a great reduction of the catalyst loading, particularly of the QAS. In parallel, several studies on the use of efficient co-catalysts immobilized on supports using a more or less sophisticated pathway have emerged in the literature. ${ }^{[32-39]}$ In the light of our recent studies dealing with the immobilization of polyoxometalates on mesoporous supports, ${ }^{[40-41]}$ the present work focuses on the covalent grafting of $\mathrm{Ni}$ and $\mathrm{Mn}$ metal-salophen complexes bearing a carboxylic acid group onto propylaminefunctionalized mesoporous silica of the SBA-15 type (Figure 1). In particular, the strategy developed allowed the straightforward immobilization of the metal-salophen cocatalysts onto the inorganic support, and, the comparison of their reactivity for the $\mathrm{CO}_{2}$ cycloaddition onto styrene oxide, in homogeneous and heterogeneous conditions.

\section{Results and Discussion}

Here, in continuity with our previous work $^{[40-41]}$ on metal complexes immobilization, the strategy used consisted in the coupling of complementary functions, one (amino group) at the oxide support (amino group) and the second at the termination of the organic salophen ligand. To do so, two different metal complexes (with either $\mathrm{Ni}^{\prime \prime}$ or $\left\{\mathrm{Mn}^{\prime \prime \prime}-\mathrm{Cl}\right\}^{2+}$ ) were prepared with a salophen ligand bearing a remote carboxylic acid function. Comparison of the co-catalytic reactivity of the two complexes in solution and after their immobilization was performed for the cycloaddition of $\mathrm{CO}_{2}$ onto styrene oxide in the presence of ${ }^{n-} \mathrm{Bu}_{4} \mathrm{NBr}$ for the preparation of styrene carbonate.

\subsection{Synthesis and characterization of the ligand $\mathrm{H}_{2}$ Salophen and of its $\mathrm{Ni}$ (II) and $\mathrm{Mn}$ (III) complexes}

A convenient salophen ligand that meets all the criteria is $\mathrm{N}, \mathrm{N}^{\prime}$-bis(3,5-di-tert-butylsalicylidene)-1-carboxy-3,4- phenylene-diamine, denoted $\mathrm{H}_{2}$ Salophen (1, Figure 2) whose synthesis, in the present study, was adapted from the literature. ${ }^{[42]}$

Hence, the Schiff-base ligand 1 was synthesized with $95 \%$ yield (see $\mathrm{SI}$ for the details of the preparation) using a classical condensation reaction of 1,2-diamino-4-carboxybenzene with 2 equivalents of 3,5-di-tert-butyl-2-hydroxybenzaldehyde (3,5-di-tert-butylsalicylaldehyde). It is noteworthy that this reaction required the presence of $\mathrm{Zn}^{2+}$ that played the dual role of a templating agent and a Lewis acid that was not recovered in the final product. The ligand 1 was characterized in mass spectrometry (HRMS) by a molecular peak at $\mathrm{m} / \mathrm{z}\left([\mathrm{M}+\mathrm{H}]^{+}\right)=585.37$ (Figure S1). The ${ }^{1} \mathrm{H}$ NMR spectrum (Figure S2) was consistent with the literature ${ }^{[42-43]}$ showing several characteristic peaks, among which two groups of singlets were attributed respectively to the imine functions $(-\mathrm{HC}=\mathrm{N}-$ at 9.08 and $9.02 \mathrm{ppm})$ and the phenol groups (13.69 and $13.61 \mathrm{ppm}$ ). The formation of the imine functions was also attested in IR spectroscopy by the absence of the $v_{(\mathrm{NH} 2)}$ bands of the initial 1,2-diamino-4-carboxybenzene at 3400 and $3487 \mathrm{~cm}^{-1}$ and by the occurrence of the $v_{(-\mathrm{HC}=\mathrm{N}-)}$ band at $1686 \mathrm{~cm}^{-1}$.

Many transition metal complexes with Schiff-Base ligands were used in the literature for the $\mathrm{CO}_{2}$ cycloaddition onto epoxides. In the present work, we focused our attention on $\mathrm{Ni}^{2+}$ and $\mathrm{Mn}^{3+}$ complexes. While many examples of cocatalysts based on $\mathrm{Mn}^{3+}$ salen/salophen/porphyrin complexes have been reported, ${ }^{[4-47]}$ those based on $\mathrm{Ni}^{2+}$ are scarce ${ }^{[48]}$ Furthermore, the Salophen-Ni (2) complex obtained by reaction of ligand 1 with $\mathrm{NiCl}_{2} \cdot 6 \mathrm{H}_{2} \mathrm{O}$ displays a square planar geometry in which the $\mathrm{Ni}^{2+}$ ion was found diamagnetic. It was thus possible to characterize complex 2, in contrast to the Mn one, by ${ }^{1} \mathrm{H}$ NMR spectroscopy in solution, but also by ${ }^{13} \mathrm{C}$ CP-MAS NMR spectroscopy in view of its subsequent immobilization.

In the case of the Salophen-Ni (2) complex synthesis, the procedure described in the literature was significantly modified. Indeed, the synthesis reported by Hey-Hawkins and co-workers was a one-pot reaction from the starting reagents (1,2-diamino-4-carboxybenzene and 3,5-di-tert-butylsalicylaldehyde) in the presence of $\mathrm{a} \mathrm{Ni}^{2+}$ source replacing the
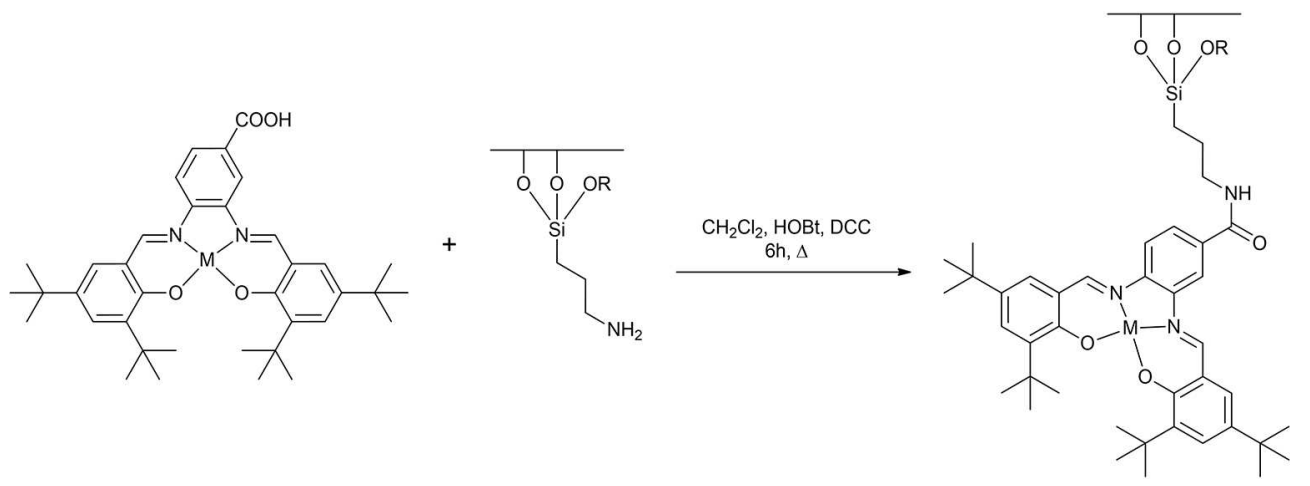

Figure 1. Covalent grafting strategy to anchor metal-salophen ( $\mathrm{N}, \mathrm{N}^{\prime}$-bis(3,5-di-tert-butylsalicylidene)-1-carboxy-3,4-phenylene-diamine) complexes onto propylamine-functionalized SBA-15 silica ( $\mathrm{HOBt}=1$-hydroxy-1H-benzotriazole; $\mathrm{DCC}=N, N^{\prime}$-dicyclohexylcarbodiimide). 


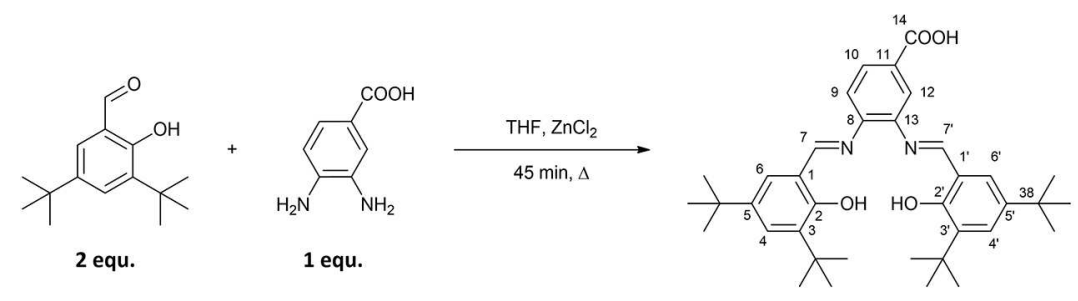

$\mathrm{H}_{2}$ Salophen ligand (1)

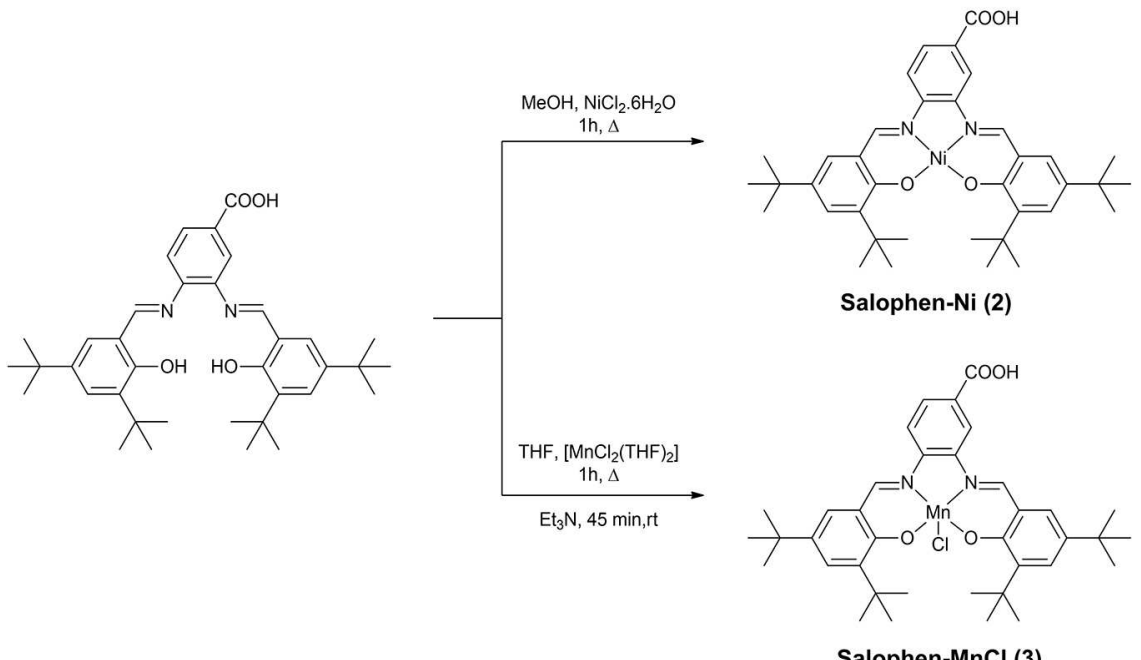

Figure 2. Routes synthesis of $\mathrm{N}, \mathrm{N}^{\prime}$-bis(3,5-di-tert-butylsalicylidene)-1-carboxy-3,4-phenylene-diamine ( $\mathrm{H}_{2} \mathrm{Salophen} \mathrm{ligand} \mathrm{1,} \mathrm{top)} \mathrm{and} \mathrm{its} \mathrm{complexation} \mathrm{leading}$ to Salophen-Ni (2) and Salophen-MnCl (3).

templating $\mathrm{Zn}^{2+}$ ion ${ }^{42}$. However, we found that his procedure led to low yields and to mixtures of different reaction products. We thus turned to the direct complexation of $\mathrm{Ni}^{2+}$ ions by the non-metallated ligand 1 in dry methanol. This procedure, which was also used for the complexation of $\mathrm{Mn}^{3+}$, finally led to 51 and $88 \%$ yield of Salophen-Ni (2) and Salophen- $\mathrm{MnCl}$ (3), respectively with high purity, as attested by HRMS (Figure S4 and Figure S5) and ${ }^{1} \mathrm{H}$ NMR (for the salophen-Ni (2), Figure S3). In the Salophen- $\mathrm{MnCl}$ complex (3), the $\mathrm{Mn}^{3+}$ displays a square pyramid five-coordination, the coordination sphere being completed with a chloride anion. Complexes $\mathbf{2}$ and $\mathbf{3}$ were characterized in mass spectrometry (HRMS) by a molecular peak respectively at $\mathrm{m} / \mathrm{z}$ $\left([\mathrm{M}-\mathrm{H}]^{-}\right)=639.27$ for the salophen-Ni 2 (Figure S4) and at $\mathrm{m} / \mathrm{z}\left([\mathrm{M}-\mathrm{Cl}]^{+}\right)=637.28$ for the Salophen-MnCl 3 (Figure S5), in accordance with the literature. ${ }^{[42]}$

The ${ }^{1} \mathrm{H}$ NMR spectrum of Salophen-Ni (2) (Figure S3) confirmed its diamagnetism. We did not observe any broadening of the peaks, as expected in the case of a paramagnetic system. It is noteworthy that the two singlets assigned to the $-\mathrm{OH}$ groups of ligand 1 were not found in the spectrum of complex 2, thus confirming the complexation of $\mathrm{Ni}^{2+}$ by the oxygen of the two phenol groups. Furthermore, the $\mathrm{Ni}$ complexation was emphasized by the shift of all the peaks of the salophen ligand in comparison with those of the free ligand 1.
2.2. Synthesis and characterization of $\left\{\mathrm{NH}_{2}\right\}-\mathrm{SBA}-15$ and of the covalently immobilized $\mathrm{Ni}^{2+}(2)$ and $\mathrm{Mn}^{3+}(3)$ catalysts

The amino-functionalized SBA-15 (for short $\left\{\mathrm{NH}_{2}\right\}-\mathrm{SBA}-15$ ) was obtained by the functionalization of a pre-formed SBA15 silica ${ }^{[49]}$ with 3-aminopropyltriethoxysilane (Scheme S1), as described previously, targeting $4 \mathrm{mmolg}^{-1} \cdot{ }^{[50-51]}$ The thermogravimetric curve of $\left\{\mathrm{NH}_{2}\right\}-\mathrm{SBA}-15$ (Figure 3) obtained under air from room temperature up to $700^{\circ} \mathrm{C}$ shows two weight losses. The first one (ca. $3 \%$ ), under $100^{\circ} \mathrm{C}$ (not shown here), can be attributed to the loss of water molecules weakly adsorbed on the silica surface whereas the second one $(13 \%$, $100-600^{\circ} \mathrm{C}$ ) was assigned to the loss of aminopropyl functions. This analysis demonstrated that $\left\{\mathrm{NH}_{2}\right\}-\mathrm{SBA}-15$ is functionalized with $2.3 \mathrm{mmol}$ of $\left\{\mathrm{NH}_{2}\right\} \mathrm{g}^{-1}$ (c.a. $58 \%$ incorporation yield). The general formula of $\left\{\mathrm{NH}_{2}\right\}-\mathrm{SBA}-15$ is then $\mathrm{H}_{2} \mathrm{~N}\left(\mathrm{CH}_{2}\right)_{3} \mathrm{Si} / 5.8 \mathrm{SiO}_{2}$.

The covalent immobilization of $\mathrm{Mn}^{3+}$ Salen complexes onto an organically modified silica surface was previously described in the literature. ${ }^{[42-47,52]}$ However, the grafting procedures in all these examples generally required a multistep functionalization of the hybrid support and/or of the salen ligands, which does not meet the criteria for the development of sustainable catalytic processes. The grafting procedure of the two complexes in the present study was inspired by the work of Luts and $\mathrm{Papp}^{[43]}$ and by our previous 


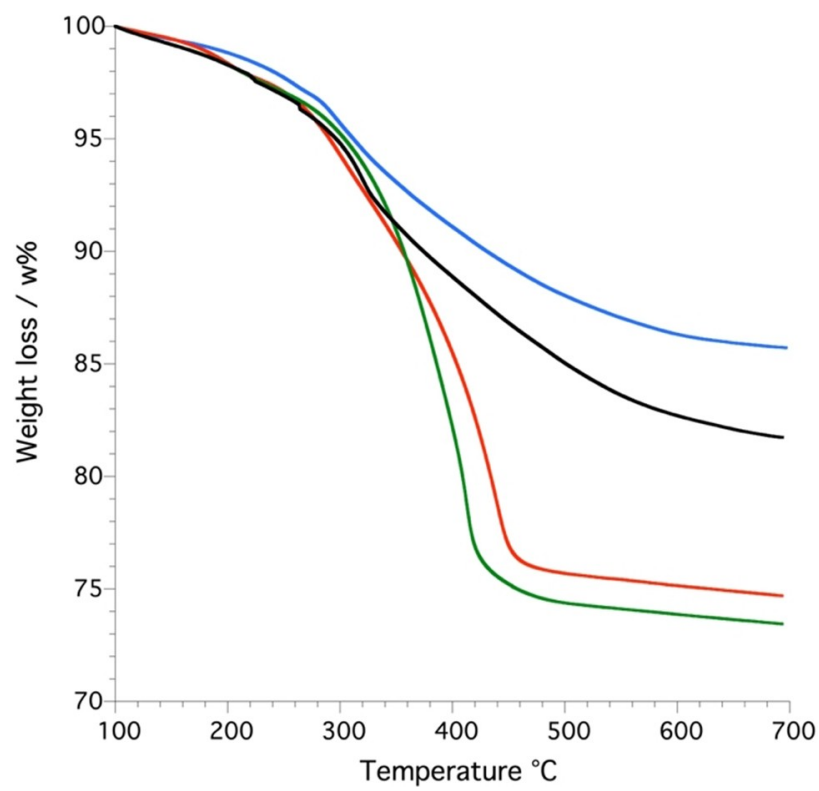

Figure 3. Weight loss \% (thermogravimetric analysis, TGA) for $\{\mathrm{NH} 2\}-\mathrm{SBA}-15$ (blue), Salophen-Ni/\{NH2\}-SBA-15 (sample without coupling agent) (black), Salophen-Ni@\{NH2\}-SBA-15 (green), Salophen-MnCl@\{NH2\}-SBA-15 (red). All the curves were normalized at $100^{\circ} \mathrm{C}$.

studies on the heterogenization of hybrid derivatives of polyoxometalates onto $\left\{\mathrm{NH}_{2}\right\}-\mathrm{SBA}-15 .^{[41]}$ In these two examples, the strategy of linkage was built on the functionalization of both the catalyst and the mesoporous silica support by complementary organic functions leading to the formation of robust and non-hydrolyzable amide groups. This choice is justified both by the efficiency and convenience of grafting aminopropyl synthons onto the $\mathrm{SiO}_{2}$ support and by the onestep preparation of the salophen ligand from commercial reagents. In the present work, the formation of an amide function by reaction between the carboxylic acid of the salophen ligand in complexes $\mathbf{2}$ and $\mathbf{3}$ and the aminopropyl functions of the $\left\{\mathrm{NH}_{2}\right\}-\mathrm{SBA}-15$ support was realized using $\mathrm{N}, \mathrm{N}^{\prime}$-dicyclohexylcarbodiimide (DCC) and 1-hydroxy-1H-benzotriazole (HOBT), in dichloromethane under refluxing conditions $\left(-\mathrm{CO}_{2} \mathrm{H}: 1, \mathrm{HOBT}: 0.3\right.$, DCC:1.4 and $-\mathrm{NH}_{2} 4.3$ for Salophen-Ni@\{ $\left.\mathrm{NH}_{2}\right\}-\mathrm{SBA}-15$ or 7.7 for Salophen-MnCl@ $\left.\left\{\mathrm{NH}_{2}\right\}-\mathrm{SBA}-15\right)$. After each synthesis, the two materials thus obtained (Salophen-Ni@\{ $\left.\mathrm{NH}_{2}\right\}-\mathrm{SBA}-15$ and Salophen-MnCl@ $\left.\left\{\mathrm{NH}_{2}\right\}-\mathrm{SBA}-15\right)$ were then extracted in a soxhlet and washed for 3 days successively with methanol and acetone to remove all the physisorbed complexes. It is noteworthy that these grafting and washing protocols were optimized in our previous work with polyoxometalates. ${ }^{[41]}$ Indeed, our past studies showed that these steps are crucial to obtain materials in which the active phases are effectively covalently grafted in order to avoid later any leaching/lixiviation phenomenon. Finally, it should be noted that, after the soxhlet treatment, the color of the samples remained dark (dark brown with $\mathrm{Mn}$ and red/purple for $\mathrm{Ni}$ ).
The weight percentages of $\mathrm{Ni}$ and $\mathrm{Mn}$ in Salophen-Ni@ $\left\{\mathrm{NH}_{2}\right\}-$ SBA-15 and Salophen-MnCl@ $\left\{\mathrm{NH}_{2}\right\}-\mathrm{SBA}-15$, respectively were determined by Atomic Absorption measurements (see details in $\mathrm{SI}$ ). These amounts are important and comparable in both materials, $1.30 \mathrm{wt} . \%$ of $\mathrm{Ni}$ in Salophen$\mathrm{Ni}\left\{\mathrm{NH}_{2}\right\}-\mathrm{SBA}-15$ and 1.06 wt.\% of $\mathrm{Mn}$ in Salophen-MnCl@ $\left\{\mathrm{NH}_{2}\right\}-$ SBA-15, corresponding to grafting yields respectively equal to $52 \%(\mathrm{Ni})$ and $68 \%(\mathrm{Mn})$ regarding the initial $\mathrm{Ni}$ or $\mathrm{Mn}$ loadings. Such values were confirmed indirectly by thermogravimetric analyses (TGA, Figure 3). Indeed, it was possible to get a reasonable estimation of the effective amount of Salophen-Ni/Mn in the final materials by subtracting the loss weight of the propylamine functions present in the starting $\left\{\mathrm{NH}_{2}\right\}-\mathrm{SBA}-15$ (see details in SI). The wt.\% of Ni or $\mathrm{Mn}$ in the materials was estimated to 1.30 and $1.03 \%$ respectively, in good accordance with the results of the atomic absorption measurements. This corresponds to $0.22 \mathrm{mmol}$ of $\mathrm{Ni}^{2+}$ per gram of Salophen-Ni@\{ $\left.\mathrm{NH}_{2}\right\}-\mathrm{SBA}-15$ and $0.19 \mathrm{mmol}$ of $\{\mathrm{MnCl}\}^{2+}$ per gram of Salophen-MnCl@ $\left\{\mathrm{NH}_{2}\right\}-\mathrm{SBA}-15$. It is noteworthy that the initial $\mathrm{Ni}^{2+} /\left\{-\mathrm{NH}_{2}\right\}$ functions and $\{\mathrm{MnCl}\}^{2+} /\left\{-\mathrm{NH}_{2}\right\}$ functions ratios described in the experimental part correspond to optimized conditions for both systems. In other words, an increase or a decrease of these ratios did not allow an increase of $\mathrm{Ni}^{2+}$ or $\{\mathrm{MnCl}\}^{2+}$ loadings in the final materials.

In order to evaluate the efficiency of the covalent grafting of the complexes onto the surface, a blank test was done in which the deposition of the Salophen-Ni (2) was carried out in the absence of a coupling agent (DCC and HOBT). This test was performed with experimental conditions (concentrations, temperature, duration of the experiment and work up) similar to those used in the presence of the coupling agent. After the washing step (4 days using a soxhlet in methanol and acetone), this control sample was visually different as the resulting solid had a light red color. TGA analyses, displayed on Figure 3, were also performed on this sample for sake of comparison. As expected, the amount of Salophen-Ni was found significantly lower in the absence of the coupling agents $\left(\mathrm{Ni} \%_{\text {weight }}=0.40 \%\right)$. When DCC and HOBT are used, all these data led us to envisage a strong linkage of the Salophen-Ni/MnCl complexes with silica in Salophen-Ni@ $\left\{\mathrm{NH}_{2}\right\}-$ SBA-15 and Salophen-MnCl@ $\left\{\mathrm{NH}_{2}\right\}-$ SBA-15 that differs clearly from a simple physical adsorption. This also shows that this protocol is relevant as regards the immobilization of this type of co-catalyst. Therefore, it validates in a more general way our covalent grafting strategy on mesoporous support 1) to limit the lixiviation phenomena during subsequent catalytic tests and 2) to increase the loading rate of the metal-salophen complexes in the catalytic materials.

The ${ }^{13} \mathrm{C}$ CP-MAS NMR spectrum of complex 2 in its solid state showed a large number of peaks (Figure S6) due to its low symmetry and the absence of free rotation of the methyl groups of the ${ }^{t-}$ butyl functions (up to 37 non-equivalent carbon atoms). Despite a lower resolution of the spectrum of Salophen-Ni@\{ $\left.\mathrm{NH}_{2}\right\}-$ SBA-15 compared to the spectrum of 2, similar patterns were observed for both samples (Figure S6). In particular, the most intense peak at $31.2 \mathrm{ppm}$ (assigned to 
some methyl of the ${ }^{t-}$ butyl groups of the salophen) was clearly observed in both samples. In addition, it is noteworthy that the spectrum of Salophen-Ni@ $\left\{\mathrm{NH}_{2}\right\}-$ SBA-15 was dominated by the three peaks (topped with an asterisk) attributed to the carbon atoms of the propylamine functions of the support.

The Raman spectra of the Salophen-Ni and Salophen$\mathrm{MnCl}$ complexes in solid state were also compared to those of Salophen-Ni@\{ $\left.\mathrm{NH}_{2}\right\}-\mathrm{SBA}-15$ (Figure 4) and Salophen$\mathrm{MnCl} @\left\{\mathrm{NH}_{2}\right\}-\mathrm{SBA}-15$, respectively (Figure 5). In both cases, the two datasets clearly indicated that the spectroscopic

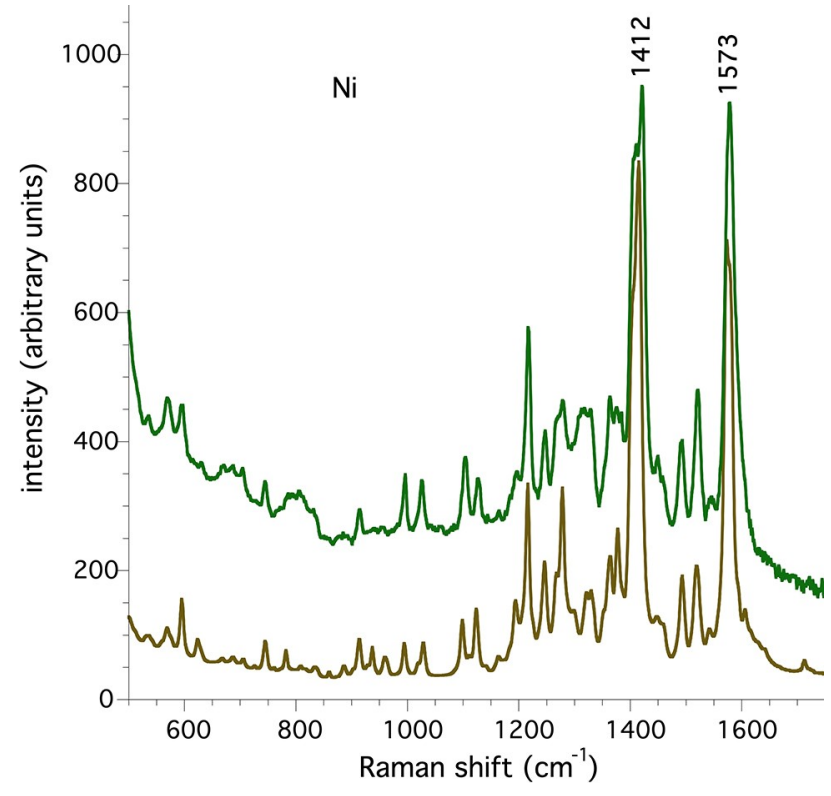

Figure 4. Raman spectra of Salophen-Ni (2) (in brown) and Salophen-Ni@ $\left\{\mathrm{NH}_{2}\right\}-\mathrm{SBA}-15$ (in green).

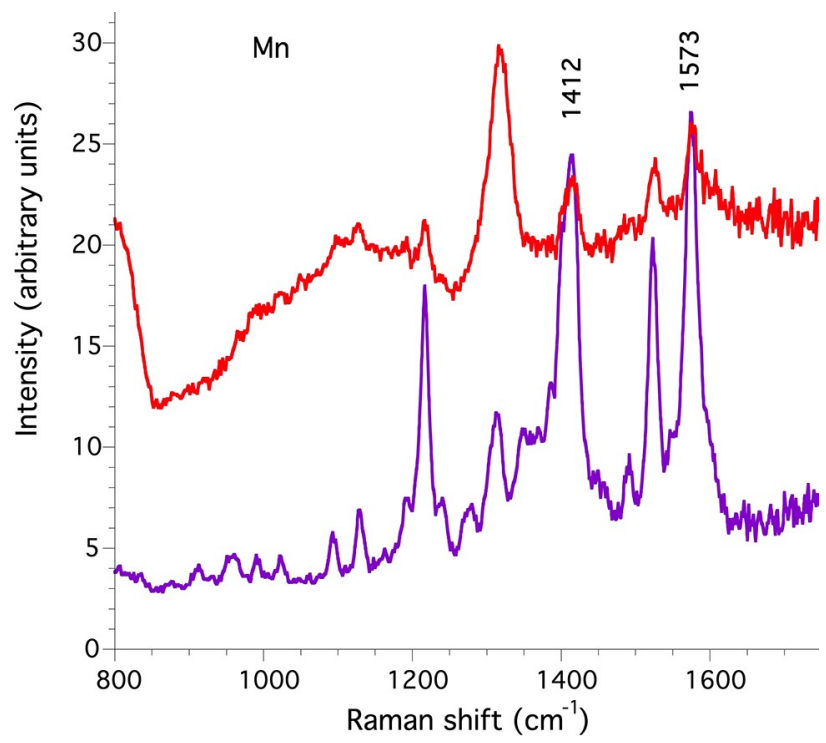

Figure 5. Salophen- $\mathrm{MnCl}$ (3) (in purple) and Salophen-MnCl@ $\left\{\mathrm{NH}_{2}\right\}-\mathrm{SBA}-15$ (in red). footprints of the supported complexes are identical to those of the pure complexes in the solid state. This confirmed that the integrity of both complexes was maintained after surface grafting, even though the spectrum of Salophen-MnCl@ $\left\{\mathrm{NH}_{2}\right\}-$ SBA-15 was less well defined, probably due to fluorescence phenomena under Raman beam. It is noteworthy that Raman spectra of Base-Schiff compounds are complex, displaying many bands and consequently are difficult to index in detail. However, by comparison with the data obtained on the parent complex without ${ }^{t-}$ Butyl and carboxylic groups (i.e. N,N'-bis(salicylaldehyde)-1,2-phenylenediamine-nickel(II)), ${ }^{[53-54]}$ it was possible to identify and assign the most intense bands at $1412\left(\delta_{\mathrm{HC}=\mathrm{N}}\right)$ and $1573 \mathrm{~cm}^{-1}$ ( $v_{\mathrm{C}=\mathrm{C}}$ aromatic) on the spectra of both the Salophen-Ni and the Salophen- $\mathrm{MnCl}$ complexes.

The Salophen-Ni@\{ $\left.\mathrm{NH}_{2}\right\}-$ SBA-15 and Salophen-MnCl@ $\left\{\mathrm{NH}_{2}\right\}-$ SBA-15 materials were also characterized by HighResolution Transmission Electronic Microscopy (HR-TEM), after microtome cutting (Figure 6 and Figure 7). For both samples, the micrographs showed that the grafting of the Salophen complexes did not alter the porosity of the support.

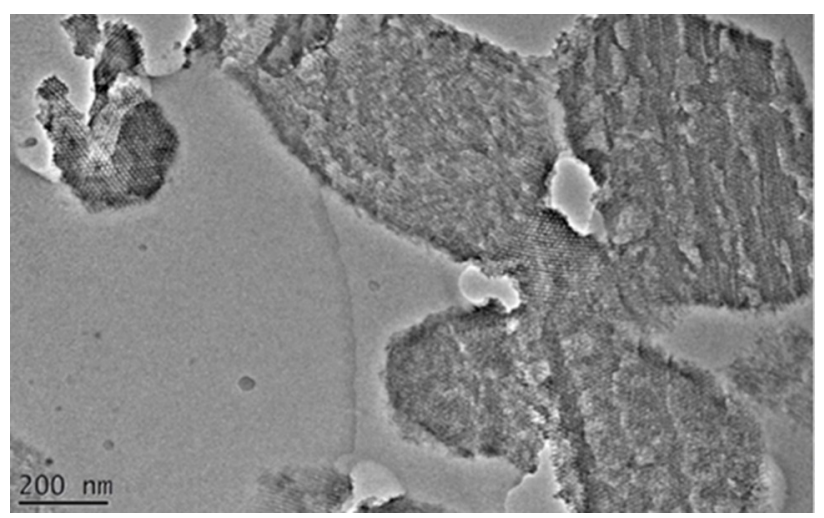

Figure 6. HR-TEM micrograph of Salophen-Ni@\{NH2\}-SBA-15 after microtome cutting.

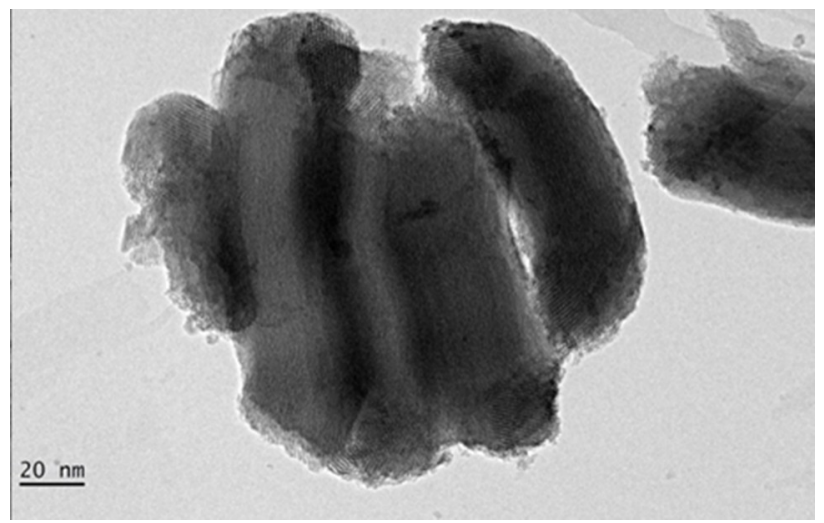

Figure 7. HR-TEM micrograph of Salophen-MnCl@\{NH2\}-SBA-15 after microtome cutting. 
The $\mathrm{N}_{2}$ adsorption-desorption isotherms of the SBA-15based materials (Figure 8) exhibited characteristic type IV patterns with $\mathrm{H}_{1}$ hysteresis confirming that all materials were constituted of mesoporous channels of relatively uniform diameter.

The pore properties of the materials at the different stages of their preparation were determined from their nitrogen adsorption-desorption isotherms using the Brunauer-Emmet-Teller (BET) and the Barret-Joyner-Halenda (BJH) models (Table 1).

As expected, the textural parameters of the mesoporous materials significantly decreased after each functionalization step: the final BET specific surface areas were respectively $350 \mathrm{~m} 2 . \mathrm{g}^{-1}$ for for Salophen-Ni@\{NH2\}-SBA-15 and $300 \mathrm{~m} 2 . \mathrm{g}^{-1}$ for Salophen-MnCl@\{NH2\}-SBA-15 (see Figure 57 ). However, this remains compatible with their utilization in anchored homogeneous catalysis.

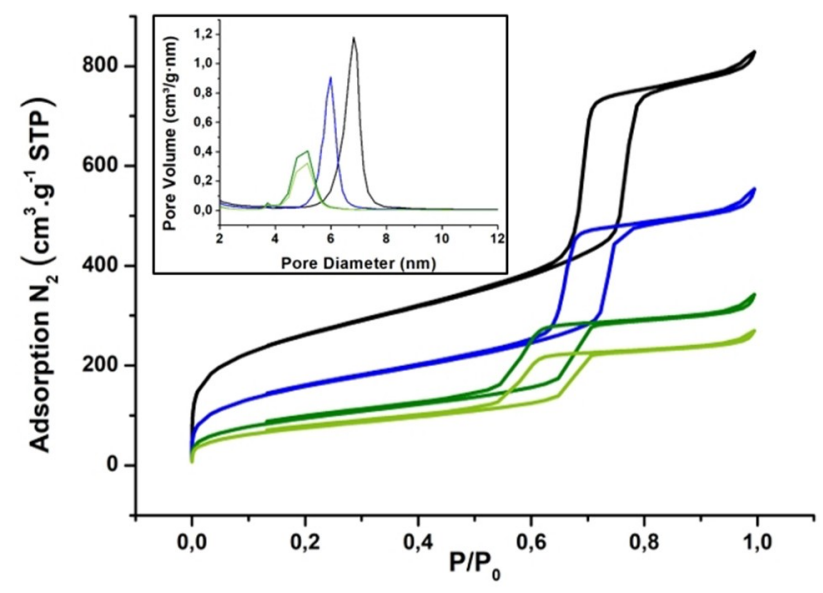

Figure 8. Nitrogen adsorption-desorption isotherms (77 K) of SBA-15 (black), $\left\{\mathrm{NH}_{2}\right\}-\mathrm{SBA}-15$ (blue), and Salophen-Ni@ $\left\{\mathrm{NH}_{2}\right\}-\mathrm{SBA}-15$ before (dark green) and after 4 catalytic cycles (light green) with pores size distribution curves (inset).

\begin{tabular}{|c|c|c|c|}
\hline Sample & $\begin{array}{l}\mathrm{S}_{\mathrm{BET}}^{[\mathrm{a}]} \\
{\left[\mathrm{m}^{2} \mathrm{~g}^{-1}\right]}\end{array}$ & $\begin{array}{l}\text { Pore } \\
\text { vol. }^{[\mathrm{b}]} \\
{\left[\mathrm{cm}^{3} \mathrm{~g}^{-1}\right]}\end{array}$ & $\begin{array}{l}\text { Average pore di- } \\
\text { ameter }^{[\mathrm{b}]}[\mathrm{nm}]\end{array}$ \\
\hline SBA-15 & 900 & 1.12 & 6.2 \\
\hline$\left\{\mathrm{NH}_{2}\right\}-\mathrm{SBA}-15$ & 530 & 0.63 & 5.7 \\
\hline 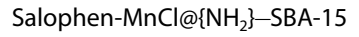 & 300 & 0.45 & 5.4 \\
\hline Salophen-Ni@\{NH $\left.\mathrm{NH}_{2}\right\}-\mathrm{SBA}-15$ & 350 & 0.48 & 5.1 \\
\hline 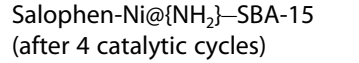 & 280 & 0.38 & 5.0 \\
\hline
\end{tabular}

[a] Use of the BET model for $\mathrm{P} / \mathrm{P}^{0}<0.25$; [b] Use of the $\mathrm{BJH}$ model for the treatment of the desorption branch with $2<$ pore range $<26 \mathrm{~nm}$.
2.3. Comparison of the co-catalytic activity of the Salophen-type complexes in the styrene oxide conversion into styrene carbonate in homogeneous and heterogeneous conditions

\subsubsection{Homogeneous conditions}

The formation of styrene carbonate from styrene epoxide and $\mathrm{CO}_{2}$ (Scheme 1) was firstly studied in homogeneous conditions. We thus used for this ${ }^{n-} \mathrm{Bu}_{4} \mathrm{NBr}$ and the $\mathrm{Ni} / \mathrm{Mn}-\mathrm{Cl}$ Salophen ( 2 and 3 ) complexes respectively as the catalyst and co-catalysts in benzonitrile. The reaction was performed in an autoclave under 15 bars of $\mathrm{CO}_{2}$ at $120^{\circ} \mathrm{C}$ and monitored by Gas-Chromatography and ${ }^{1} \mathrm{H}$ NMR spectroscopy after $3 \mathrm{~h}$, $7 \mathrm{~h}$ and $23 \mathrm{~h}$.

As already reported, ${ }^{[55]}$ a fairly good conversion of styrene oxide was observed with ${ }^{n-} \mathrm{Bu}_{4} \mathrm{NBr}$ alone (no metal cocatalysts) after $7 \mathrm{~h}(81 \%$, see entry 1 Table 2$)$ using a styrene oxide: ${ }^{n-} \mathrm{Bu}_{4} \mathrm{NBr}$ molar ratio of 60 . However, the reaction slowed considerably afterwards ( $84 \%$ after $23 \mathrm{~h}$ ). Typical experiments were performed with a total volume of liquid phase equal to $14 \mathrm{~mL}(13.3 \mathrm{~mL}$ of benzonitrile and $0.7 \mathrm{~mL}$ of styrene oxide) in the $100 \mathrm{~mL}$ vessel. It is noteworthy that this corresponds to the optimized reaction conditions, since the yield in styrene carbonate was shown to be significantly dependent on the $\mathrm{CO}_{2}$ pressure but also on the number of moles of $\mathrm{CO}_{2}$ available in the vessel. Thus, using the same styrene oxide concentration $\left(0.44 \mathrm{~mol} \mathrm{~L}^{-1}\right)$ and the same styrene oxide: ${ }^{n-} \mathrm{Bu}_{4} \mathrm{NBr}(60: 1)$ molar ratio, but tripling the<smiles>c1ccc(C2CO2)cc1</smiles>

Cat.: ${ }^{n-} \mathrm{Bu}_{4} \mathrm{NBr}$
$\stackrel{\mathrm{Co}-\text { cat.: salophen-Ni/MnC }}{\mathrm{CO}_{2}(15 \text { bar }), \text { Benzonitrile }}$

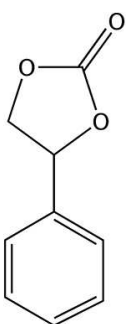

Scheme 1. $\mathrm{CO}_{2}$ cycloaddition onto styrene oxide.

\begin{tabular}{|c|c|c|c|c|c|}
\hline \multirow[t]{2}{*}{ Entry } & \multirow[t]{2}{*}{ Catalyst } & \multirow[t]{2}{*}{ Co-catalyst } & \multicolumn{3}{|c|}{ [\%] Styrene conv. } \\
\hline & & & $3[\mathrm{~h}]$ & $7[\mathrm{~h}]$ & $23[h]$ \\
\hline 1 & ${ }^{n-} \mathrm{Bu}_{4} \mathrm{NBr}$ & - & 62 & 81 & 84 \\
\hline 2 & ${ }^{n-} \mathrm{Bu}_{4} \mathrm{NBr}$ & Salophen-Ni (2) & 65 & 85 & 100 \\
\hline 3 & ${ }^{n-} \mathrm{Bu}_{4} \mathrm{NBr}$ & Salophen- $\mathrm{MnCl}$ (3) & 100 & 100 & 100 \\
\hline 4 & - & Salophen-Ni (2) & / & / & 0 \\
\hline 5 & - & Salophen- $\mathrm{MnCl}$ (3) & l & l & 2 \\
\hline 6 & ${ }^{n-} \mathrm{Bu}_{4} \mathrm{NBr}$ & Jacobsen catalyst (commercial) & 100 & 100 & 100 \\
\hline 7 & ${ }^{n-} \mathrm{Bu}_{4} \mathrm{NBr}$ & 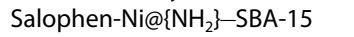 & 80 & 98 & 100 \\
\hline 8 & ${ }^{n-} \mathrm{Bu}_{4} \mathrm{NBr}$ & Salophen-MnCl@\{NH $\left.\mathrm{NH}_{2}\right\}$ SBA-15 & 80 & 100 & 100 \\
\hline 9 & ${ }^{n-} \mathrm{Bu}_{4} \mathrm{NBr}$ & $\left\{\mathrm{NH}_{2}\right\}-\mathrm{SBA}-15^{[\mathrm{b}]}$ & 81 & 86 & 98 \\
\hline
\end{tabular}

[a] Conditions: Styrene oxide $(6.1 \mathrm{mmol}),{ }^{n-} \mathrm{Bu}_{4} \mathrm{NBr}(0.1 \mathrm{mmol})$, homogeneous or supported Salophen-M $(0.05 \mathrm{mmol}$ of metal) in $13.3 \mathrm{~mL}$ of benzonitrile at $120^{\circ} \mathrm{C}$ under 15 bars of $\mathrm{CO}_{2}$. [b] For experimental details see the Supporting Information. 
volume of the solution in the closed vessel, led to a significant decrease in styrene oxide conversion from $81 \%$ to $40 \%$ after $7 \mathrm{~h}$ due to the reduction of the molar excess of $\mathrm{CO}_{2}$ from 7 to 1.5 .

In all experiments, the possible presence of polycarbonates (potentially obtained by co-polymerization of styrene oxide with styrene carbonate) was checked by ${ }^{1} \mathrm{H}$ and ${ }^{13} \mathrm{C}$ NMR spectroscopy. In any cases, no trace of polymers was detected. This was confirmed by the mass balance determination by GC using mesitylene as an internal standard. Thereafter, considering a selectivity of $100 \%$, the total yield in styrene carbonate was assimilated to the conversion of styrene oxide.

Keeping similar reaction conditions (15 bar of $\mathrm{CO}_{2}$ at $120^{\circ} \mathrm{C}$ and $\mathrm{CO}_{2}$ : epoxide $\left.=7: 1\right)$ and using metal salophen complexes $\mathbf{2}$ or $\mathbf{3}$ as co-catalysts with a co-catalyst: catalyst ratio of $1: 2$ (Table 2 , entries 2 and 3), a complete conversion of styrene oxide could be reached. We have checked that both complexes were not able to catalyse alone the $\mathrm{CO}_{2}$ cycloaddition onto styrene oxide (Table 2, entries 4 and 5). The rate increase in the presence of salophen complexes was found to be strongly metal dependent. While the gain in the styrene oxide conversion was relatively modest with the Salophen-Ni (2) (conversion of 65 and $85 \%$ after respectively 3 and $7 \mathrm{~h}$ ), it was significant after $3 \mathrm{~h}$ (100\% conversion) in the case of the $\mathrm{Mn}^{\text {III }}$ derivative (3). The styrene carbonate yield obtained with the latter was found to be identical to that obtained with the commercial Mn Jacobsen catalyst (Table 2, entry 6) under the same conditions, which means that the diamine used in the synthesis of the salophen was less critical than the metal. An additional test performed with 3 and ${ }^{n-} \mathrm{Bu}_{4} \mathrm{NBr}$ showed actually that, after one hour at $120^{\circ} \mathrm{C}$, the styrene oxide conversion was $96 \%$. Even if the catalytic activity of the $n-\mathrm{Bu}_{4} \mathrm{NBr} / \mathrm{Salophen}-\mathrm{Ni}$ (2) system in homogeneous conditions is slightly lower than that obtained with $n-\mathrm{Bu}_{4} \mathrm{NBr} / \mathrm{Salophen}-\mathrm{MnCl}$ (3), it is noteworthy that this result deserved special emphasis since examples of $\mathrm{Ni}$ cocatalysts for the $\mathrm{CO}_{2}$ cycloaddition are scarce.

\subsubsection{Heterogeneous conditions}

The activity of the two anchored co-catalysts (Salophen-Ni@ $\left\{\mathrm{NH}_{2}\right\}-$ SBA-15 or Salophen-MnCl@ $\left.\left\{\mathrm{NH}_{2}\right\}-\mathrm{SBA}-15\right)$ was studied in the same reaction conditions (Table 2, entries 7 and 8) with $0.44 \mathrm{M}$ styrene oxide keeping ${ }^{n-} \mathrm{Bu}_{4} \mathrm{NBr}$ as a homogeneous catalyst with a styrene oxide: ${ }^{n-} \mathrm{Bu}_{4} \mathrm{NBr}$ molar ratio of 60 and using amounts of supported Salophen-Ni (2) or Salophen$\mathrm{MnCl}$ (3) rigorously analogous to those employed in Table 2 (entries 2 and 3) for soluble Salophen-Ni (2) and Salophen$\mathrm{MnCl}$ (3), respectively. With Salophen-Ni@\{ $\left.\mathrm{NH}_{2}\right\}-\mathrm{SBA}-15$ and Salophen-MnCl@ $\left\{\mathrm{NH}_{2}\right\}-$ SBA-15, the results obtained were comparable, allowing near complete conversion of styrene oxide after $7 \mathrm{~h}$. As early as $3 \mathrm{~h}$ of reaction, supported Salophen-Ni showed much better performance than its homogeneous counterpart. With both supported complexes, the conversion was $80 \%$ after $3 \mathrm{~h}$. Such conversion value for
Salophen-MnCl@ $\left\{\mathrm{NH}_{2}\right\}-$ SBA-15 corresponds to a slight decrease compared to what was observed for Salophen- $\mathrm{MnCl}$ tested in homogeneous conditions ( $80 \%$ conversion after $3 \mathrm{~h}$ instead of $100 \%$ ). Indeed, heterogenized (co-)catalysts are often less active at early stage than their homogeneous counterparts due to diffusion limitations. However, it is somewhat surprising to observe a significant increase in cocatalytic activity after supporting the nickel complex $(80 \%$ conversion after $3 \mathrm{~h}$ instead of $65 \%$ ). Finally, there are only a few examples of salen complexes covalently immobilised on silica whose catalytic properties have been evaluated in $\mathrm{CO}_{2}$ cycloaddition in the literature, with mainly $\mathrm{Al}, \mathrm{Cr}, \mathrm{Zn}$ or $\mathrm{Mn}$ ions. ${ }^{[33,56-59]}$ To our knowledge, no nickel heterogenized complex was described. As far as manganese complexes are concerned, comparisons are hardly made, as the experimental conditions are very different from one study to another. For instance, silylated Salen-Mn(III) covalently grafted onto silica showed interesting catalytic performances in the absence of tetraalkylammonium halide with a $95 \%$ yield in styrene carbonate after $3 \mathrm{~h}$ reaction but with very harsh reaction conditions, $140{ }^{\circ} \mathrm{C}$ under 35 bar of $\mathrm{CO}_{2} .{ }^{[59]}$

In order to better understand the differences between the homogeneous and supported $\mathrm{Ni}$ co-catalysts, we also investigated the potential co-catalytic activity of the support itself, $\left\{\mathrm{NH}_{2}\right\}-\mathrm{SBA}-15$ keeping ${ }^{n-} \mathrm{Bu}_{4} \mathrm{NBr}$ as the main catalyst (Table 2, entry 9, see details in $\mathrm{SI}$ ). It is indeed necessary to have in mind that Salophen-Ni@\{ $\left.\mathrm{NH}_{2}\right\}-$ SBA-15 and Salophen$\mathrm{MnCl} @\left\{\mathrm{NH}_{2}\right\}-\mathrm{SBA}-15$ materials contain c.a. $0.2 \mathrm{mmolg}^{-1}$ of salophen complex but also c.a. $2.1 \mathrm{mmolg}^{-1}$ of free aminopropyl groups. Working with $\left\{\mathrm{NH}_{2}\right\}-\mathrm{SBA}-15$ (without any Salen) and ${ }^{n-} \mathrm{Bu}_{4} \mathrm{NBr}$ alone, all other reaction parameters being unchanged (especially the number of amino groups), also led to a nearly complete conversion after $24 \mathrm{~h}$. Such blank test emphasized the non-innocent character of the free amino groups in Salophen-Ni@\{ $\left.\mathrm{NH}_{2}\right\}-\mathrm{SBA}-15$ and Salophen$\mathrm{MnCl} @\left\{\mathrm{NH}_{2}\right\}-\mathrm{SBA}-15$ materials since the results with ${ }^{n-} \mathrm{Bu}_{4} \mathrm{NBr} /\left\{\mathrm{NH}_{2}\right\}-\mathrm{SBA}-15$ (Table 2, entry 8 ) turned out to be systematically better than those obtained with ${ }^{n-} \mathrm{Bu}_{4} \mathrm{NBr}$ alone (Table 2, entry 1). Using Salophen-Ni@ $\left\{\mathrm{NH}_{2}\right\}-\mathrm{SBA}-15$ and Salophen-MnCl@\{ $\left.\mathrm{NH}_{2}\right\}-\mathrm{SBA}-15$, the effect of the metal complexes turned out to be significant after the first $3 \mathrm{~h}$, since a complete epoxide conversion was obtained after $7 \mathrm{~h}$ of reaction with both supported $\mathrm{Ni}$ and $\mathrm{Mn}$ co-catalysts, while the epoxide consumption, in their absence, was equal to $86 \%$ (Table 2, entry 9). Such positive influence of the free amino groups on the support was more easily observed when using Salophen-Ni due to its lower intrinsic efficiency shown in homogeneous conditions (Table 2, entry 2). Improvement of the catalytic activity of silica-supported compared to soluble phosphonium halides in $\mathrm{CO}_{2}$ cycloaddition has already been observed. ${ }^{[60]}$ In that case, the proposed explanation invoked a possible activation of the epoxide towards the halide attack owing to hydrogen bonding of the oxirane with the surface silanol groups of the support, thus playing the role of electrophilic sites. At first glance, one explanation in our case would be that similar activation of the epoxide could also occur through hydrogen 
bonding between the free aminopropyl groups of the support and styrene oxide even if the $\mathrm{N}-\mathrm{H}$ bond in $-\left(\mathrm{CH}_{2}\right)_{3}-\mathrm{NH}_{2}$ is less polar than the $\mathrm{O}-\mathrm{H}$ bond in $\equiv \mathrm{Si}-\mathrm{OH}$. A beneficial effect due the presence of such groups able to form hydrogen bonding has also been emphasized in other works. ${ }^{[61-64]}$ More generally, this behaviour is reminiscent of the anchoring mechanisms of substrates in the cavity of certain enzymes such as acetylcholinesterase. ${ }^{[65]}$ Indeed, this cavity which typically consists in a region particularly rich in $\{\mathrm{NH}\}$ amides or positively charged residues allows for insertion or positioning of a substrate and actually works as a Lewis acid site useful for activation. Another explanation for the positive effect of the functionalized support would be due to the activation of $\mathrm{CO}_{2}$ itself by the primary amine in $\left\{\mathrm{NH}_{2}\right\}-\mathrm{SBA}-15$, Salophen-Ni@ $\left\{\mathrm{NH}_{2}\right\}-\mathrm{SBA}-15$ or Salophen$\mathrm{MnCl} @\left\{\mathrm{NH}_{2}\right\}-\mathrm{SBA}-15$ even if the resulting carbamate is not the promptest to transfer $\mathrm{CO}_{2}$ to the anionic intermediate obtained from the attack of styrene oxide by bromide. ${ }^{[66]}$ Usually activated carbamates issued from tertiary amines are preferred as exemplified in the work of J. Gao et al. ${ }^{[67]}$ who reported a significant cyclocarbonate yield increase upon the addition of triethylamine. Nevertheless, some groups have reported the beneficial impact of primary amine auxiliaries in the design of homogeneous ${ }^{[62]}$ or even heterogeneous catalysts ${ }^{[66,68]}$ for the $\mathrm{CO}_{2}$ addition onto epoxides.

\subsubsection{Stability of the catalysts}

Finally, the stability of the co-catalysts was investigated in homogeneous conditions with Salophen- $\mathrm{MnCl}$ (3) (4 runs of $3 \mathrm{~h}$ with styrene oxide and $\mathrm{CO}_{2}$ replenishment without any work-up) and in heterogeneous conditions with Salophen$\mathrm{Ni} @\left\{\mathrm{NH}_{2}\right\}-$ SBA-15 (4 runs of $23 \mathrm{~h}$ separated by filtration and drying steps). The detailed operating protocols for both experiments were based on the optimized experimental conditions described in the experimental part and in Table 2 (see experimental section for details), and the results are displayed in Figure 9. In these experiments, both co-catalysts were successfully re-used without any appreciable loss of performance after respectively four cycles, leading to a nearly complete styrene conversion (from 94 to $99 \%$ ) in all cases, thus indicating an excellent stability in homogeneous and heterogeneous conditions.

Furthermore, the supported catalyst Salophen-Ni@ $\left\{\mathrm{NH}_{2}\right\}-$ SBA-15 could be characterized after the catalytic process in order to verify that the integrity of the metal complexe is maintained. For sake of illustration, the Raman spectra of Salophen-Ni@\{ $\left.\mathrm{NH}_{2}\right\}-$ SBA-15 were compared before and after 4 catalytic cycles (see supporting information Figure S8), showing the same patterns in both cases. In addition, the comparison of the textural parameters of

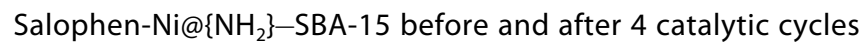
(Figure 8 and Table 1) also demonstrated that the catalytic materials were also not altered at the microscale level. Indeed, mean pore diameter values before and after catalysis

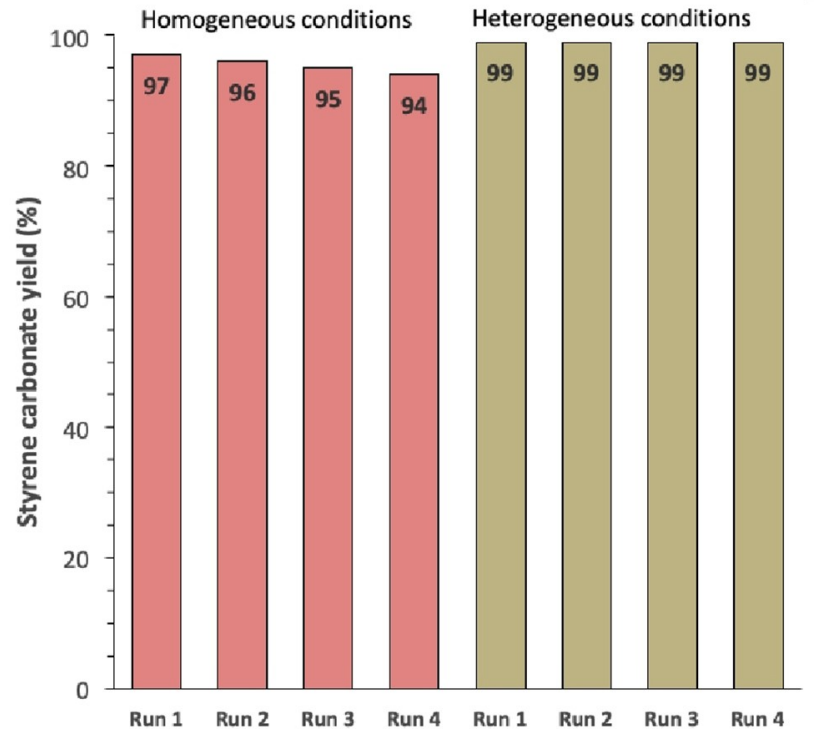

Figure 9. Styrene carbonate yield (\%) for Salophen- $\mathrm{MnCl}$ (3) (homogeneous conditions, in light red) after 1 to 4 runs of $3 \mathrm{~h}$ and for Salophen-Ni@ $\left\{\mathrm{NH}_{2}\right\}-\mathrm{SBA}-15$ (heterogeneous conditions, in light green) after 1 to 4 runs of $23 \mathrm{~h}$. Conditions: Styrene oxide $(6.1 \mathrm{mmol}),{ }^{n} \mathrm{Bu}_{4} \mathrm{NBr}(0.1 \mathrm{mmol})$, homogeneous or supported Salophen-M $(0.05 \mathrm{mmol})$ in $13.3 \mathrm{~mL}$ of benzonitrile at $120^{\circ} \mathrm{C}$ under 15 bars of $\mathrm{CO}_{2}$.

were shown to be almost unchanged while the BET surface areas and pore volumes turned out to be equivalent.

\section{Conclusion}

In this study, nickel(II) and manganese (III) complexes with the $\quad N, N^{\prime}$-bis(3,5-di-tert-butylsalicylidene)-1-carboxy-3,4phenylene-diamine (Salophen-MnCl and Salophen-Ni), bearing carboxylic acid groups on their ligands, were synthesized and fully characterized. Both were shown to work as ${ }^{n-} \mathrm{Bu}_{4} \mathrm{NBr}$ co-catalyst for the cycloaddition of $\mathrm{CO}_{2}$ onto styrene oxide, thus affording a real added value in terms of epoxide conversion $\left(100 \%\right.$ after $3 \mathrm{~h}$ of reaction at $120^{\circ} \mathrm{C}$ under 15 bar of $\mathrm{CO}_{2}$ with Salophen- $\mathrm{MnCl}$ instead of $62 \%$ without). In addition, the soluble Salophen- $\mathrm{MnCl} /{ }^{n-} \mathrm{Bu}_{4} \mathrm{NBr}$ system proved to be stable after 3 successive replenishments of the consumed styrene oxide.

Using DCC as a convenient and efficient coupling agent, Salophen- $\mathrm{MnCl}$ and Salophen-Ni were easily heterogenized, with up to $1 \mathrm{wt} . \%$ of metal at once, by amide linkage onto a SBA-15 silica bearing propylamine groups, thus affording recoverable co-catalysts. Immobilization of the less active complex in solution, Salophen- $\mathrm{Ni}$, even resulted in an enhanced co-catalytic activity ( $100 \%$ conversion of styrene oxide after $7 \mathrm{~h}$ instead of $85 \%$ in solution). This particular result paves thus the way to the utilization of (rarely used in the literature) $\mathrm{Ni}^{2+}$ catalysts for the $\mathrm{CO}_{2}$ cycloaddition onto epoxides. Furthermore, the heterogenized form of Salophen$\mathrm{Ni}$ was successfully re-used without any appreciable loss of activity over 4 runs. In addition, the preservation of the 
integrity of this co-catalyst, after the catalytic process, was demonstrated by Raman spectroscopy as well as by the measurement of the $\mathrm{N}_{2}$ desorption/absorption isotherms.

More important, this study also showed that propylamine functions at the surface of the $\left\{\mathrm{NH}_{2}\right\}-\mathrm{SBA}-15$ support alone play also a co-catalytic role for the $\mathrm{CO}_{2}$ cycloaddition reaction in the presence of ${ }^{n-} \mathrm{Bu}_{4} \mathrm{Br}$ and give rise to some synergy when using covalently grafted Salophen-Ni and ${ }^{n-} \mathrm{Bu}_{4} \mathrm{Br}$. In both cases, the origin of this effect would be due to the activation of the epoxide and/or of $\mathrm{CO}_{2}$. In conclusion, it is clear that this work is only a first step towards a completely heterogeneous catalytic system, in which the tetraalkylammonium halide catalyst and the metal-salophen co-catalyst will both be covalently anchored on the same support. However, this work is currently in progress and will be the subject of a second manuscript.

\section{Experimental Section}

\section{Synthesis and heterogenization of the precursor complexes}

Preparation of $N, N^{\prime}$-bis(3,5-di-tert-butylsalicylidene)-1-carboxy3,4-phenylene-diamine-nickel(II) (Salophen-Ni (2)). $\mathrm{H}_{2}$ Salophen ligand (1) $(1.000 \mathrm{~g}, 1.70 \mathrm{mmol}$, see preparation in Supporting Information and characterization in Figure S1 (HRMS spectrum) and Figure S2 ( ${ }^{1} \mathrm{H}$ NMR spectrum)) was dissolved in $50 \mathrm{~mL}$ of dry methanol under argon in a two-neck round-bottom flask connected to a condenser. A solution of $\mathrm{NiCl}_{2} \cdot 6 \mathrm{H}_{2} \mathrm{O}$ in excess $(1.069 \mathrm{~g}$, $4.50 \mathrm{mmol}$ ) dissolved in $30 \mathrm{~mL}$ of dry methanol was then added and the mixture was refluxed for one hour under argon. The volume of the solution was then reduced until $20 \mathrm{~mL}$ under vacuum and allowed to stand at room temperature overnight. The dark red solid (Salophen-Ni (2)) that appeared during this time was then filtered at air on a frit glass $\left(n^{\circ} 4\right)$ and washed quickly with small portions of methanol, yielding $0.550 \mathrm{~g}(51 \%) .{ }^{1} \mathrm{H}$ NMR $\left(\left[\mathrm{D}_{6}\right]\right.$ dmso, ppm, Figure $\mathrm{S} 3)$ : $\delta \mathrm{H} 8.98(1 \mathrm{H}, \mathrm{s}, \mathrm{C}(7) \mathrm{H}=\mathrm{N}), 8.91\left(1 \mathrm{H}, \mathrm{s}, \mathrm{C}\left(7^{\prime}\right)\right.$ $\mathrm{H}=\mathrm{N}), 8.72(1 \mathrm{H}, \mathrm{s}, \mathrm{C}(12) \mathrm{H}), 8.27\left(1 \mathrm{H}, \mathrm{d}^{3} \mathrm{~J}_{\mathrm{HH}}=12.0 \mathrm{~Hz}, \mathrm{C}(9) \mathrm{H}\right), 7.84$ $\left(1 \mathrm{H}, \mathrm{d},{ }^{3} \mathrm{~J}_{\mathrm{HH}}=12.0 \mathrm{~Hz}, \mathrm{C}(10) \mathrm{H}\right), 7.63\left(1 \mathrm{H}, \mathrm{d}^{4}{ }^{4} \mathrm{~J}_{\mathrm{HH}}=3.3 \mathrm{~Hz}, \mathrm{C}(6) \mathrm{H}\right), 7.49$ $\left(1 \mathrm{H}, \mathrm{d},{ }^{4} \mathrm{JHH}=2.6 \mathrm{~Hz}, \mathrm{C}\left(6^{\prime}\right) \mathrm{H}\right), 7.38\left(1 \mathrm{H}, \mathrm{d}^{4}{ }^{4} \mathrm{JHH}=3.3 \mathrm{~Hz}, \mathrm{C}(4) \mathrm{H}\right), 7.35$ $\left(1 \mathrm{H}, \mathrm{d},{ }^{4} \mathrm{JHH}=2.6 \mathrm{~Hz}, \mathrm{C}\left(4^{\prime}\right) \mathrm{H}\right), 1.41 \quad\left(18 \mathrm{H}, \mathrm{s}, \mathrm{C}(3) \mathrm{C}\left(\mathrm{CH}_{3}\right)_{3}+\mathrm{C}\left(3^{\prime}\right)\right.$ $\left.\left.\mathrm{C}\left(\mathrm{CH}_{3}\right)_{3}\right), 1.30\left(18 \mathrm{H}, \mathrm{s}, \mathrm{C}(5) \mathrm{C}\left(\mathrm{CH}_{3}\right)_{3}\right)+\mathrm{C}\left(5^{\prime}\right) \mathrm{C}\left(\mathrm{CH}_{3}\right)_{3}\right) ; \mathrm{IR}\left(\mathrm{KBr}, \mathrm{cm}^{-1}\right)$ : $3422(\mathrm{~m}), 3054(\mathrm{~m}), 2959(\mathrm{~s}), 1729(\mathrm{~s}), 1686(\mathrm{~m}), 1619(\mathrm{~s}), 1579(\mathrm{~s})$, $1523(\mathrm{~s}), 1458(\mathrm{~m}), 1426(\mathrm{~s}), 1386(\mathrm{~s}), 1359(\mathrm{~s}), 1260(\mathrm{~m}), 1200(\mathrm{~s})$, $1180(\mathrm{~s}), 1130(\mathrm{~m}), 1026(\mathrm{~m}), 788(\mathrm{~m}), 541(\mathrm{~m})$. HRMS [2-H] ${ }^{-}(\mathrm{ESI})$ : $\mathrm{m} / \mathrm{z}=639.27$ (Figure S4).

Preparation of $N, N^{\prime}$-bis(3,5-di-tert-butylsalicylidene)-1-carboxy-3,4phenylene-diamine-chloro-Manganese(III) (Salophen-MnCl (3)). $\mathrm{H}_{2}$ Salophen ligand (1) $(0.347 \mathrm{~g}, 0.60 \mathrm{mmol})$ was dissolved in $20 \mathrm{~mL}$ of dry THF under argon in a two-neck round-bottom flask connected to a condenser. $\left[\mathrm{MnCl}_{2}(\mathrm{THF})_{2}\right](0.160 \mathrm{~g}, 0.60 \mathrm{mmol})$ was then added to the solution and the mixture was stirred at room temperature for $1 \mathrm{~h}$, then refluxed for $20 \mathrm{~min}$. After cooling at room temperature, triethylamine $(0,12 \mathrm{~g}, 1.20 \mathrm{mmol}, 0,17 \mathrm{~mL})$ was then added and the mixture stirred for another $45 \mathrm{~min}$. The volume of the solution was then reduced up to $10 \mathrm{~mL}$ under vacuum and allowed to stand at room temperature overnight. After this period, a white powder (triethylammonium chloride) was filtered and discarded. The brown solution was evaporated, leading to a brown solid (Salophen- $\mathrm{MnCl}(3)$ ) that can be recrystallized in THF (yield: $0.350 \mathrm{~g}, 0,50 \mathrm{mmol}, 88 \%)$. IR $\left(\mathrm{KBr}, \mathrm{cm}^{-1}\right): 3416(\mathrm{~m}), 2958(\mathrm{~m}), 1680$ $(\mathrm{sh}), 1610$ (s), 1573 (s), 1466 (s), 1392 (s), 1361 (s), 1325 (s), 1249 (s), $1198(\mathrm{~s}), 1178(\mathrm{~s}), 1097$ (s), 1026 (s), 807 (s), 781 (s), 548 (m). HRMS $[3-\mathrm{Cl}]^{+}(\mathrm{ESI}): \mathrm{m} / \mathrm{z}=637.28$ (Figure S5).

Covalent grafting of Salophen-Ni (2) onto $\left\{\mathrm{NH}_{2}\right\}-\mathrm{SBA}-15$. $\left\{\mathrm{NH}_{2}\right\}-\mathrm{SBA}-15\left(0.30 \mathrm{~g},\left[-\mathrm{RNH}_{2}\right]=2.3 \mathrm{mmol} \mathrm{g}^{-1}\right.$, corresponding to $0.69 \mathrm{mmol}$ of $\left\{-\mathrm{RNH}_{2}\right\}$ functions, see synthesis in $\mathrm{SI}$ ) and Salophen$\mathrm{Ni}$ (2) $(0.105 \mathrm{~g}, 0.16 \mathrm{mmol})$ were dried under vacuum overnight in two schlenk tubes. Then, Salophen-Ni (2) was dissolved in dichloromethane (DCM, $3 \mathrm{~mL}$ ). In parallel, 1-hydroxy-1H-benzotriazole (HOBT, $0.007 \mathrm{~g}, 0.05 \mathrm{mmol}$ ) and $N, N^{\prime}$-dicyclohexylcarbodiimide (DCC, $0.05 \mathrm{~g}, 0.22 \mathrm{mmol}$ ) were dissolved in $2 \mathrm{~mL}$ of DCM and the resulting solution was added to the solution of 2 . The mixture was stirred for $40 \mathrm{~min}$ at room temperature. Meanwhile, $10 \mathrm{~mL}$ of DCM were added to $\left\{\mathrm{NH}_{2}\right\}-\mathrm{SBA}-15$. After $40 \mathrm{~min}$, the previous mixture of 2, HOBT and DCC was transferred to the suspension of $\left\{\mathrm{NH}_{2}\right\}-\mathrm{SBA}-$ 15 and refluxed for $6 \mathrm{~h}$ under $\mathrm{N}_{2}$. Then, the solvent was evaporated until dryness and the resulting red powder was washed successively with refluxing methanol and acetone using a Soxhlet, respectively for 3 days and $24 \mathrm{~h}$. Salophen-Ni@ $\left\{\mathrm{NH}_{2}\right\}-\mathrm{SBA}-15(0.32 \mathrm{~g})$ was thus obtained as a dark red purple powder $\left(\mathrm{Ni} \%_{\text {weight }}=1.30 \%\right.$ determined by TGA $\left(10.3 \% \mathrm{~mol} \mathrm{Ni} / \mathrm{mol}-\mathrm{NH}_{2}\right)$ corresponding to a $\mathrm{Ni}$ grafting yield of $52 \%)$.

Covalent grafting of Salophen-MnCl (3) onto $\left\{\mathrm{NH}_{2}\right\}-\mathrm{SBA}-15$. $\left\{\mathrm{NH}_{2}\right\}-$ SBA-15 $\left(1.5 \mathrm{~g},\left[-\mathrm{RNH}_{2}\right]=2.3 \mathrm{mmol} \mathrm{g}^{-1}\right.$, corresponding to $3.45 \mathrm{mmol}$ of $\left\{-\mathrm{RNH}_{2}\right\}$ functions) and Salophen- $\mathrm{MnCl}$ (3) $(0.30 \mathrm{~g}$, $0.45 \mathrm{mmol}$ ) were dried under vacuum overnight in two schlenk tubes. Then, Salophen- $\mathrm{MnCl}$ (3) was dissolved in DCM, $6 \mathrm{~mL}$, and 1hydroxy-1H-benzotriazole $(0.021 \mathrm{~g}, 0.138 \mathrm{mmol})$ and $\mathrm{N}, \mathrm{N}^{\prime}$-dicyclohexylcarbodiimide (DCC, $0.135 \mathrm{~g}, 0.66 \mathrm{mmol}$ ) were added to this solution. The mixture was stirred for $40 \mathrm{~min}$ at room temperature. Meanwhile, $10 \mathrm{~mL}$ of DCM were added to $\left\{\mathrm{NH}_{2}\right\}-\mathrm{SBA}-15$. After $40 \mathrm{~min}$, the previous mixture of 3, HOBT and DCC was transferred to the suspension of $\left\{\mathrm{NH}_{2}\right\}-\mathrm{SBA}-15$ and refluxed for $6 \mathrm{~h}$ under $\mathrm{N}_{2}$. The solvent was then evaporated until dryness and the resulting brown powder was washed successively with refluxing methanol and acetone using a Soxhlet, respectively for 3 days and $24 \mathrm{~h}$. Salophen-MnCl@\{ $\left.\mathrm{NH}_{2}\right\}-$ SBA-15 (1.44 g) was thus obtained as a dark brown powder $\left(\mathrm{Mn} \%_{\text {weight }}=1.03 \%\right.$ determined by TGA $\left(8.2 \% \mathrm{~mol} \mathrm{Mn} / \mathrm{mol}-\mathrm{NH}_{2}\right)$ corresponding to a $\mathrm{Mn}$ grafting yield of $68 \%)$.

\section{Protocols for the catalysis tests}

After each catalytic test, the resulting solutions or suspensions were analysed by gas chromatography (GC, see details in Supporting Information) after dilution (samples of $25 \mu \mathrm{L}$ diluted in $10 \mathrm{~mL}$ of $\mathrm{CH}_{2} \mathrm{Cl}_{2}$ ).

Experiments in homogeneous conditions (including stability test). In a $50 \mathrm{~mL}$ Teflon container, $0.7 \mathrm{~mL}$ of styrene oxide $(6.1 \mathrm{mmol})$ and $0.031 \mathrm{~g}(0.100 \mathrm{mmol})$ of ${ }^{n-} \mathrm{Bu}_{4} \mathrm{NBr}$ were dissolved in $13.3 \mathrm{~mL}$ of benzonitrile. Except for the tests performed in the absence of co-catalysts, $0.031 \mathrm{~g}$ of Salophen-Ni (or $0.033 \mathrm{~g}$ Salophen- $\mathrm{MnCl})(0.05 \mathrm{mmol}))$ was added and the resulting mixture was stirred for $5 \mathrm{~min}$ at room temperature. Then, the autoclave was pressurized at $11 \mathrm{bar}$ of $\mathrm{CO}_{2}$ (corresponding to $41 \mathrm{mmol}$ ). The temperature was then increased up to $120^{\circ} \mathrm{C}$ in $40 \mathrm{~min}$, leading to a $\mathrm{CO}_{2}$ pressure of 15 bar. Heating was then prolonged for 3, 7 or $23 \mathrm{~h}$ and the reaction was quenched by cooling the autoclave into a water-ice mixture.

For the stability test, the reaction was carried out for $3 \mathrm{~h}$, then quenched as described above. After analysis by GC, a new batch of styrene oxide $(0.7 \mathrm{~mL}, 6.1 \mathrm{mmol})$ was introduced in the recovered Teflon container and the reaction mixture was stirred for $5 \mathrm{~min}$ at room temperature. Then, the autoclave was pressurized as described before. This procedure was repeated 3 times. 
Experiments with the supported complexes (including recyclability test). The protocols were identical with the exception of the mass of co-catalysts added. $0.218 \mathrm{~g}$ of Salophen-Ni@\{NH $\left.\mathrm{NH}_{2}\right\}-\mathrm{SBA}-15$ (or $0.259 \mathrm{~g}$ Salophen-MnCl@ $\left\{\mathrm{NH}_{2}\right\}-\mathrm{SBA}-15$ ), corresponding to $0.05 \mathrm{mmol}$ of immobilized metal salophen complexes, was suspended in the benzonitrile solution. Then, the autoclave was pressurized as described before. After 3,7 or $23 \mathrm{~h}$, the reaction was quenched by cooling the autoclave into a water-ice mixture, and the reaction mixture was filtered on a büchner funnel, in order to separate the supported catalyst.

For the recyclability test, the reaction was carried out for $23 \mathrm{~h}$ and the solid recovered after each attempt was carefully washed by acetone, dried in an oven at $50^{\circ} \mathrm{C}$ for $12 \mathrm{~h}$ and weighted to check the mass after each run. This procedure was repeated three times.

Other synthesis procedures and all the details on the different characterization techniques are reported in the Supporting Information: HRMS (ESI) spectrum and ${ }^{1} \mathrm{H}$ NMR spectrum of $\mathrm{H}_{2}$ salophen ligand 1, HRMS (ESI) spectrum and ${ }^{1} \mathrm{H}$ NMR spectrum of Salophen$\mathrm{Ni} \mathrm{(2),} \mathrm{HRMS} \mathrm{(ESI)} \mathrm{spectrum} \mathrm{of} \mathrm{Salophen-} \mathrm{MnCl}$ (3), scheme of the synthetic procedure for the preparation of $\left\{\mathrm{NH}_{2}\right\}-\mathrm{SBA}-15,{ }^{13} \mathrm{C} \mathrm{CP}-$ MAS NMR spectra of Salophen-Ni and Salophen-Ni@ $\left\{\mathrm{NH}_{2}\right\}-\mathrm{SBA}-15$, Nitrogen adsorption-desorption isotherms of Salophen-MnCl@ $\left\{\mathrm{NH}_{2}\right\}-$ SBA-15 and Raman spectra of Salophen-Ni@ $\left\{\mathrm{NH}_{2}\right\}-\mathrm{SBA}-15$ before and after 4 catalytic cycles.

\section{Acknowledgements}

This work benefited from the support of the project OxCyCat- $\mathrm{CO}_{2}$ (ANR-17-CE06-0009) of the Agence Nationale de la Recherche (ANR) for a PhD fellowship to Mr Matthieu Balas, for financial reward for Mr Sébastien Beaudoin and more generally for funding this work. The authors want also to acknowledge the Centre National de la Recherche Scientifique (CNRS), Sorbonne Université, Mrs Delphine Talbot, from Laboratoire de Physicochimie des Electrolytes et Nanosystèmes Interfaciaux (PHENIX, UMR CNRS 8234, Sorbonne Université) for her help in atomic absorption measurements for Ni/Mn analyses and Mr Jean-Marc Krafft, from Laboratoire de Réactivité de Surface (LRS, UMR CNRS 7197, Sorbonne Université) for his help in Raman spectroscopy.

\section{Conflict of Interest}

The authors declare no conflict of interest.

Keywords: Cyloaddition $\cdot \mathrm{CO}_{2}$ valorization - Hybrid catalysts $\cdot$ Mesoporous materials $\cdot$ Salen derivatives

[1] A. W. Kleij, M. North, A. Urakawa, ChemSusChem 2017, 10, 1036-1038.

[2] M. North, ChemSusChem 2019, 12, 1763-1765.

[3] M. Aresta, Coord. Chem. Rev. 2017, 334, 150-183.

[4] M. Peters, B. Köhler, W. Kuckshinrichs, W. Leitner, P. Markewitz, T. E. Müller, ChemSusChem 2011, 9, 1216-1240.

[5] G. Laugel, C. Carvalho Rocha, P. Massiani, T. Onfroy, F. Launay, Adv. Chem. Lett. 2013, 1, 195-214.

[6] $\square \square$ Dear author, please add authors $\square \square$, ChemSusChem 2017, 10, 1034-1297.

[7] C. Chauvier, T. Cantat, ACS Catal. 2017, 7, 2107-2115.
[8] S. Sopeña, G. Fiorani, C. Martín, A. W. Kleij, ChemSusChem 2015, 8, 3248-3254.

[9] M. Cokoja, M. E. Wilhelm, M. H. Anthofer, W. A. Herrmann, F. E. Kühn, ChemSusChem 2015, 8, 2436-2454.

[10] M. Alves, B. Grignard, S. Gennen, C. Detrembleur, C. Jerome, T. Tassaing, RSC Adv. 2015, 5, 53629-53636.

[11] Z. Z. Yang, L. N. He, C. X. Miao, S. Chanfreau, Adv. Synth. Catal. 2010, $352,2233-2240$.

[12] Y. Zhou, S. Hu, X. Ma, S. Liang, T. Jiang, B. Han, J. Mol. Catal. A 2008, 284, 52-57.

[13] B. Chatelet, L. Joucla, J. P. Dutasta, A. Martinez, K. C. Szeto, V. Dufaud, J. Am. Chem. Soc. 2013, 135, 5348-5351.

[14] C. Miceli, J. Rintjema, E. Martin, E. C. Escudero-Adán, C. Zonta, G. Licini, A. W. Kleij, ACS Catal. 2017, 7, 2367-2373.

[15] D. Darensbourg, Chem. Rev. 2007, 107, 2388-2410.

[16] P. Lan, L. E. White, E. S. Taher, P. E. Guest, M. G. Banwell, A. C. Willis, J. Nat. Prod. 2015, 78, 1963-1968.

[17] X. Xiaoding, J. A. Moulijn, Energy Fuels 1996, 10, 305-325.

[18] J. Melendez, M. North, R. Pasquale, Eur. J. Inorg. Chem. 2007, 3323-3326.

[19] X. Zhang, Y. B. Jia, X. B. Lu, B. Li, H. Wang, L. C. Sun, Tetrahedron Lett. 2008, 49, 6589-6592.

[20] J. Rintjema, L. P. Carrodeguas, V. Laserna, S. Sopena, A. W. Kleij, Top. Organomet. Chem. 2016, 53, 39-71.

[21] L. Cuesta-Aluja, A. Campos-Carrasco, J. Castilla, M. Reguero, A. M. Masdeu-Bulto, A. Aghmiz, J. CO2 Util. 2016, 16, 10-22.

[22] J. W. Comerford, I. D. V. Ingram, M. North, X. Wu, Green Chem. 2015, 17, 1966-1987.

[23] M. Aresta, A. Dibenedetto, Dalton Trans. 2007, 2975-2992.

[24] A. Kamphuis, F. Picchioni, P. P. Pescarmona, Green Chem. 2019, 21, 406448.

[25] M. Alves, B. Grignard, R. Mereau, C. Jerome, T. Tassaing, C. Detrembleur, Catal. Sci. Technol. 2017, 7, 2651-2684.

[26] A. Mirabaud, J.-C. Mulatier, A. Martinez, J.-P. Dutasta, V. Dufaud, Catal. Today 2017, 281, 387-391.

[27] C. Carvalho Rocha, T. Onfroy, J. Pilme, A. Denicourt-Nowicki, A. Roucoux, F. Launay, J. Catal. 2016, 333, 29-39.

[28] L. Cuesta-Aluja, M. Djoufak, A. Aghmiz, R. Rivas, L. Christ, A. MasdeuBulto, J. Mol. Catal. A 2014, 381, 161-170.

[29] M. Djoufak, PhD thesis, dir. L. Christ, University of Lyon 2013.

[30] T. Ema, Y. Miyazaki, S. Koyama, Y. Yano, T. Sakai, Chem. Commun. 2012, 48, 4489-4491.

[31] J. A. Castro-Osma, K. J. Lamb, M. North, ACS Catal. 2016, 6, 5012-5025.

[32] J. Melendez, M. North, P. Villuendas, C. Young, Dalton Trans. 2011, 40, 3885-3902.

[33] P. A. Carvalho, J. W. Comerford, K. J. Lamb, M. North, P. S. Reiss, Adv. Synth. Catal. 2019, 361, 345-354.

[34] S. Wei, Y. Tang, G. Xu, X. Tang, Y. Ling, R. Li, Y. Sun, React. Kinet. Catal. Lett. 2009, 97, 329-333.

[35] A. Heckel, D. Seebach, Helv. Chim. Acta 2002, 85, 913-926.

[36] S. Xiang, Y. Zhang, Q. Xin, C. Li, Chem. Commun. 2002, 2696-2697.

[37] H. Zhang, S. Xiang, J. Xiao, C. Li, J. Mol. Catal. A 2005, 238, 175-184.

[38] L. Saikia, D. Srinivas, P. Ratnasamy, Microporous Mesoporous Mater. 2007, 104, 225-235.

[39] G. Trusso Sfrazzetto, S. Millesi, A. Pappalardo, R. M. Toscano, F. P. Ballistreri, G. A. Tomaselli, A. Gulino, Catal. Sci. Technol. 2015, 5, 673679.

[40] F. Bentaleb, O. Makrygenni, D. Brouri, C. Coelho Diogo, A. Mehdi, A. Proust, F. Launay, R. Villanneau, Inorg. Chem. 2015, 54, 7607-7616.

[41] O. Makrygenni, D. Brouri, A. Proust, F. Launay, F. Launay, R. Villanneau, Microporous Mesoporous Mater. 2019, 278, 314-321.

[42] T. Luts, R. Frank, W. Suprun, S. Fritzsche, E. Hey-Hawkins, H. Papp, J. Mol. Catal. A 2007, 273, 250-258.

[43] T. Luts, H. Papp, Kinet. Catal. 2007, 48, 176-182.

[44] F. Jutz, J.-D. Grunwaldt, A. Baiker, J. Mol. Catal. A 2009, 297, 63-72.

[45] J. L. S. Milani, A. M. Meireles, B. N. Cabral, W. de A Bezerra, F. T. Martins, D. Carvalho da Silva Martins, R. Pavao das Chagas, J. CO2 Util. 2019, 30, 100-106.

[46] L. Cuesta-Aluja, J. Castilla, A. M. Masdeu-Bulto, C. A. Henriques, M. J. F. Calvete, M. M. Pereira, J. Mol. Catal. A 2016, 423, 489-494.

[47] R. Srivastava, T. H. Bennur, D. Srinivas, J. Mol. Catal. A 2005, 226, 199205.

[48] Y. Fan, J. Li, Y. Ren, H. Jiang, Eur. J. Inorg. Chem. 2017, 43, 4982-4989.

[49] F. Chiker, F. Launay, J. P. Nogier, J. L. Bonardet, Appl. Catal. A 2003, 243, 309-321. 
[50] M. Boutros, G. Shirley, T. Onfroy, F. Launay, Appl. Catal. A 2011, 394, $158-165$.

[51] R. Villanneau, A. Marzouk, Y. Wang, A. Ben Djamaa, G. Laugel, A. Proust, F. Launay, Inorg. Chem. 2013, 52, 2958-2965.

[52] M. Schley, S. Fritzsche, P. Lönnecke, E. Hey-Hawkins, Dalton Trans. 2010, 39, 4090-4106.

[53] M. Datta, D. H. Brown, W. E. Smith, Spectrochim. Acta Part A 1983, 39, 37-41.

[54] T. A. de Toledo, P. S. Pizani, L. E. da Silva, A. M. R. Teixeira, P. T. C. Freire, J. Mol. Struct. 2015, 1097, 106-111.

[55] S. Foltran, J. Alsarraf, F. Robert, Y. Landais, E. Cloutet, H. Cramail, T. Tassaing, Catal. Sci. Technol. 2013, 3, 1046-1055.

[56] C. Baleizão, B. Gigante, M. J. Sabater, H. Garcia, A. Corma, Appl. Catal. A 2002, 228, 279-288

[57] M. Ramin, F. Jutz, J.-D. D. Grunwaldt, A. Baiker, J. Mol. Catal. A 2005, 242, 32-39.

[58] M. Alvaro, C. Baleizao, D. Das, E. Carbonell, H. García, J. Catal. 2004, 228, 254-58.

[59] F. Jutz, J. D. Grunwaldt, A. Baiker, J. Mol. Catal. A 2008, 279, 94-103.
[60] T. Takahashi, T. Watahiki, S. Kitazume, H. Yasuda, T. Sakakura, Chem. Commun. 2006, 1664-1666.

[61] L.-Q. Wei, B.-H. Ye, Inorg. Chem. 2019, 58, 4385-4393.

[62] T. Werner, N. Tenhumberg, J. CO2 Util. 2014, 7, 39-45.

[63] J. Liang, Y.-B. Huang, R. Cao, Coord. Chem. Rev. 2019, 378, 32-65.

[64] M. Liu, X. Wang, Y. Jiang, J. Sun, M. Arai, Catal. Rev. Sci. Eng. 2019, 61, 214-269.

[65] Y. Zhang, J. Kua, J. A. McCammon, J. Am. Chem. Soc. 2002, 124, 1057210577.

[66] R. Srivastava, D. Srinivas, P. Ratnasamy, Microporous Mesoporous Mater. 2006, 90, 314-326.

[67] J. Gao, L. li, C. Cui, M. A. Ziaee, Y. Gong, R. Sa, H. Zhong, RSC Adv. 2019, 9, 13122-13127.

[68] Y. Li, X. Zhang, J. Lan, P. Xu, J. Sun, Inorg. Chem. 2019, 58, 13917-13926.

Manuscript received: February 18, 2021

Revised manuscript received: March 15, 2021 


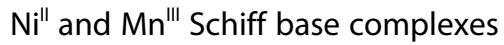
bearing a pending carboxylic group were grafted onto a mesoporous amino-functionalized SBA-15 silica. The co-catalytic behaviour of the grafted complexes with ${ }^{n-} \mathrm{Bu}_{4} \mathrm{NBr}$ was evaluated in the $\mathrm{CO}_{2}$ cycloaddition onto styrene oxide. Upon immobilization at the surface of the SBA-15, the performances of the $\mathrm{Ni}^{2+}$ complex were enhanced, hence highlighting a synergistic effect with the amine functions of the support.

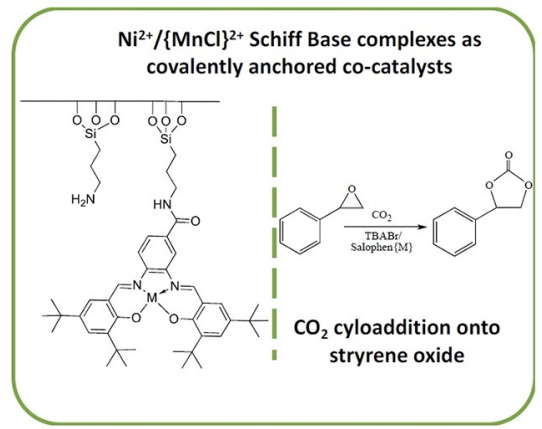

M. Balas, S. Beaudoin, Prof. A. Proust, Prof. F. Launay*, Dr. R. Villanneau*

$1-12$

Advantages of Covalent Immobilization of Metal-Salophen on AminoFunctionalized Mesoporous Silica in Terms of Recycling and Catalytic Activity for $\mathrm{CO}_{2}$ Cycloaddition onto Epoxides

Launay, Villanneau and co-workers investigate the catalytic properties of nickel(II) and manganese(II) Schiff base complexes @ipcm_sorbonne

Share your work on social media! EurJIC has added Twitter as a means to promote your article. Twitter is an online microblogging service that enables its users to send and read short messages and media, known as tweets. Please check the pre-written tweet in the galley proofs for accuracy. If you, your team, or institution have a Twitter account, please include its handle @username. Please use hashtags only for the most important keywords, such as \#catalysis, \#nanoparticles, or \#proteindesign. The ToC picture and a link to your article will be added automatically, so the tweet text must not exceed 250 characters. This tweet will be posted on the journal's Twitter account (follow us @EurJIC) upon publication of your article in its final (possibly unpaginated) form. We recommend you to re-tweet it to alert more researchers about your publication, or to point it out to your institution's social media team.

\section{ORCID (Open Researcher and Contributor ID)}

Please check that the ORCID identifiers listed below are correct. We encourage all authors to provide an ORCID identifier for each coauthor. ORCID is a registry that provides researchers with a unique digital identifier. Some funding agencies recommend or even require the inclusion of ORCID IDs in all published articles, and authors should consult their funding agency guidelines for details. Registration is easy and free; for further information, see http://orcid.org/.

Matthieu Balas

Sébastien Beaudoin

Prof. Anna Proust

Prof. Franck Launay

Dr. Richard Villanneau http://orcid.org/0000-0003-1465-3494 